\section{Community Preventive Services Task Force Recommends Interventions Engaging Community Health Workers for Diabetes Prevention}

The Community Preventive Services Task Force recently posted new information on its website: "Diabetes: Interventions Engaging Community Health Workers." The information is available at https:/www.thecommunityguide.org/findings/ diabetes-interventions-engaging-community-health-workers.

Established in 1996 by the U.S. Department of Health and Human Services, the task force is an independent, nonfederal, uncompensated panel of public health and prevention experts whose members are appointed by the director of CDC. The task force provides information for a wide range of decision makers on programs, services, and policies aimed at improving population health. Although CDC provides administrative, research, and technical support for the task force, the recommendations developed are those of the task force and do not undergo review or approval by CDC.

\section{5th Anniversary of National Program of Cancer Registries, 1992-2017}

This year marks the 25th anniversary of the Cancer Registries Amendment Act (Public Law 102-515), which established the National Program of Cancer Registries (NPCR) administered by CDC (1). NPCR collects high quality data on cancer occurrence (including the type, extent, and location of the cancer), type of initial treatment, and outcomes. NPCR supports cancer registries in 45 states, the District of Columbia, Puerto Rico, and U.S. Pacific Island jurisdictions, covering 96\% of all cancers diagnosed in the United States.

This week, $M M W R$ features a Surveillance Summary and a weekly report that use NPCR data. The Surveillance Summary describes national cancer incidence and death rates for 68 cancer types among men and 72 among women, and statespecific rates for common cancers and trends for all cancer sites combined (2). The weekly report summarizes incidence rates for common cancers tracked in Healthy People 2020 and cancers that can be prevented through limiting risk factors (tobacco use, alcohol use) or increasing vaccination (against human papilloma virus) (3), and highlights states' use of registry data to advance public health. Together, these reports demonstrate how public health planners in states, territories, and tribes use NPCR data to measure progress and target action for cancer prevention and control.

CDC annually provides cancer surveillance data via several products (3). This month, for the first time, CDC released a public use research NPCR data set, available at https:/www. cdc.gov/cancer/npcr/public-use. Detailed, de-identified information on several million cancer cases from 1999 to 2013 is now available, providing researchers and the interested public the opportunity to analyze these data to better understand cancer, inform coordinated efforts to address cancer through prevention, and evaluate progress in cancer control.

\section{References}

1. Fisher R, Haenlein M. Legislative authorizations for cancer registries. In: National Cancer Institute, National Institutes of Health. State cancer legislative database update. Bethesda, MD: US Department of Health and Human Services, Public Health Service, National Institutes of Health, National Cancer Institute; 1991:8-15.

2. Singh SD, Henley SJ, Ryerson AB. Surveillance for cancer incidence and mortality-United States, 2013. MMWR Surveill Summ 2017;66(No. SS-4).

3. Henley SJ, Singh SD, King JB, O’Neil ME, Wilson R, Ryerson AB. Invasive cancer incidence and survival-United States, 2013. MMWR Morb Mortal Wkly Rep 2017;66:69-75. 


\section{Vol. 65, No. 52}

In the report "Human Rabies - Puerto Rico, 2015," on page 1476, the first sentence under the Summary heading "What is added by this report?" should have read "A man aged 54 years who was bitten by a mongoose in October 2015 was the first person to acquire rabies from a mongoose in the United States or U.S. territories, confirming mongoose rabies as a public health threat."

\section{Vol. 66, Nos. SS-1 and SS-2}

In the Surveillance Summaries "Leading Causes of Death in Nonmetropolitan and Metropolitan Areas - United States, 1999-2014" and "Reducing Potentially Excess Deaths from the Five Leading Causes of Death in the Rural United States," an error occurred in Figure 5 and Figure 3, respectively. In the last panel of bar charts (stroke), the colors for the left-most set of bars (public health region 1) should be reversed.

In addition, the following person should have been listed as the Guest Editor in the masthead and the Acknowledgments: Robin M. Wagner, PhD, MS, Guest Editor. 